\title{
Confidentiality, the law in England, and sexually transmitted diseases
}

\author{
MARTIN D TALBOT \\ From the Department of Genitourinary Medicine, Royal Hallamshire Hospital, Sheffield
}

\section{Introduction}

In the age of information technology and social conscience, traditional medical confidentiality is under threat. We are bombarded daily with intimate details of people's private lives by the media, and personal health information does not seem to be exempt. Until now it has been accepted that confidences divulged in good faith by a patient to his medical adviser will be respected as such and will not be disclosed to persons not directly concerned with the medical care of that patient (the third party).

A survey of most of the important ethical codes will confirm the belief in the autonomy of the individual, and this autonomy will include a person's right to privacy. The law has long recognised that there are areas of anyone's private life in which any reasonable person could fittingly demand to be left alone. ${ }^{1}$ Though violation of a person's privacy is not of itself a punishable offence in English law, the courts do recognise some invasions of privacy that are actionable, and exploring a person's private sexual life is clearly one such form.

Catterall succinctly summed up the situation with regard to medical confidentiality and the service in the United Kingdom for sexually transmitted diseases (STD). ${ }^{2}$ The ethic of medical confidence has been governed for thousands of years by the Hippocratic oath, which asserts: "and whatsoever I shall see or hear in the course of my profession, as well as outside of my profession in my intercourse with men, if it be what should not be published abroad, I will never divulge, holding such things to be holy secrets." In the era of "priestly medicine," however, such sentiments were most likely concerned primarily with the main-

Address for reprints: Dr M D Talbot, Department of Genitourinary Medicine, Royal Hallamshire Hospital, Glossop Road, Sheffield S10 2JF

Accepted for publication 26 November 1985 tenance of a medical closed shop. It has been adjudged that such consideration also applied to the Hippocratic school of thought, ${ }^{3}$ and that basing what is accepted as an altruistic ethic on the oath is like "building upon sand." We see, however, a more modern, and one hopes, more altruistic, reaffirmation of this principle in the Declaration of Geneva (as amended at Sydney, 1958): "I will respect the secrets which are confided in me, even after the patient has died."

What then is the legal and moral basis for medical confidentiality? There is, in fact, very little legal support for the doctrine of confidence between doctor and patient. There is no statute law concerning privacy as such in the United Kingdom, and thus any legal right to confidentiality must lie either in common law or contract (in the National Health Service (NHS) contract law between doctor and patient would not necessarily apply, S Gaskill, personal communication). If confidence then assumes the mantle of moral or ethical doctrine the words of Lord Coleridge, Chief Justice, may apply: "A legal common law duty is nothing else than the enforcing by law of that which is a moral obligation without legal enforcement."'s The legal rights of the patient then depend on the court's view of the moral obligation of the physician.

In practical terms, if there were no professional code of secrecy, patients would not confide in their doctor, doctors would not consult with one another, and professional skills would diminish on both accounts. ${ }^{4}$ Such a situation would be so unsatisfactory that the Law Commission has suggested that breach of confidence be defined as a wrongful act by legislation. ${ }^{6}$ Interestingly, medical confidentiality in France and Belgium is absolute and is protected in the criminal code (France: penal code, Article 378. Belgium: penal code, Article 458).

It is not widely recognised, however, that medical confidence is not privileged in law - that is, doctors can be compelled to divulge professional secrets if ordered to do so by a crown court judge. The same is true, incidentally, of confidence held by a priest: the only 
privileged information is that between lawyer and client. Failure to divulge under such circumstances would invoke proceedings for contempt against the doctor. In practice judges are most sympathetic to the doctor's dilemma in this respect and would, if asked, receive that part of the evidence held by the doctor in writing, or verbally in camera.

\section{THE EXCEPTION TO THE CODE OF PRIVACY}

There are certain well defined exceptions to the rule of medical privacy, which are discussed at length by the British Medical Association (BMA). ${ }^{7}$ The most important exceptions to the rule of disclosure of confidential information about a patient are: when the patient gives the doctor informed consent to disclose; the due process of the law (see above); where there is a statutory duty to disclose - for example, under the infectious diseases acts; or when the doctor reasons in good faith that disclosure will be benefit to the patient.

THE SPECIAL POSTION WITH REGARD TO SEXUALLY TRANSMITTED DISEASES AND THE VENEREAL DISEASE REGULATIONS

From time to time in this country, STDs (or venereal diseases) have been recognised not only as personal problems for the individuals concerned but as problems of major importance to public health. So, for example, in the fifteenth century persons in Edınburgh suspected of being syphilitic had to assemble on the Sand of Leith at a designated time for transportation to quarantine on an offshore island. ${ }^{8}$ Earlier in the same year (1497) the burgh authorities in Aberdeen published a regulation clearly recognising the venereal element in the newly arrived syphilis. Being a little more enthusiastic than the good citizens of Edinburgh they called for: "All light women to decist from their vice and syne of venerie," and to work for their own support on pain of being branded. The Contagious Diseases Acts were passed in the nineteenth century to contain the problem of prostitution and venereal disease in certain British garrison towns (Contagious Diseases Acts (England), 1864, 1866, 1869). No doubt Moses had the public's health in mind when he ensured that his women with an issue be "put aside" for seven days.

Doubtless, the Royal Commission on Venereal Diseases also considered the public's health when it reported in 1916 and caused the local government board to make the Venereal Diseases Regulations of 1916. Under the Regulations, which defined venereal disease as syphilis, gonorrhoea, and soft chancre, the board instructed local councils to provide facilities for the treatment of these diseases at the public's expense. Article $11^{2}$ of the Regulations states: "Any information obtained in regard to any persons treated under such a scheme approved in pursuance of this Article should be regarded as confidential." The sentiments of this Article have been reaffirmed in every modification of the Venereal Diseases Regulations since: The National Health Service (Venereal Diseases) Regulations 1948 SI No 2517 Article 3; The National Health Service (Venereal Diseases) Regulations 1968 SI No 1624 Article 3; The National Health Service (Venereal Diseases) Regulations 1974 SI No 29 Article 2 . The purpose of the enactment of such confidentiality was to encourage the patient to attend for specialist advice and treatment.

The 1974 Regulations update the situation to include STDs rather than just venereal diseases. The exception to the rule regarding non-disclosure is set out in the 1974 Regulations: disclosure is permitted to "a medical practitioner, or to a person employed under the direction of a medical practitioner in connection with the treatment of persons suffering from such disease for the prevention of the spread thereof and ... for the purpose of such treatment and prevention." The memorandum, which accompanied the 1968 regulations (HM (68) 84, section 27) opined that medical and other staff involved in contact tracing are not liable for defamation.

\section{THE DATA PROTECTION COMMITTEE}

There has been increasing concern at the rapid growth in the number of agencies now concerned with the diagnosis, treatment, and management of patients. They all need speedy access to reliable data, much of which is stored mechanically; and both the Younger committee on privacy ${ }^{9}$ and the Lindop committee on data processing ${ }^{10}$ pointed this out. The Government eventually acted and introduced the Data Protection Bill, but its safeguards against unjustified disclosure of medical information were seen to be seriously defective. As a result, an interprofessional working party was set up under the chairmanship of Sir Douglas Black. The government was at first remarkably unhelpful; the Bill had passed through the Lords and was well on the way to the committee stage ${ }^{11}$ before the group persuaded the Minister of Health to issue a code of guidance in draft form and to invite comments from various interested bodies. ${ }^{12}$ The key issue of the draft code is that before a disclosure is made the doctor responsible for the patient should be consulted. Disclosure is permitted without the doctor's permission, however, to an "officer of the health authority", which obviously has implications for genitourinary medicine as it is so vague and opposed to the sentiments of the Venereal Diseases Regulations. Interestingly, the House of Lords has recently upheld the right of a lay councillor in local government to see confidential medical information in social service committee records, even though the councillor had nothing to do with the case and was not even a member of the committee. ${ }^{13}$ 
This "eleventh hour" success by the medical profession is not the only such example, and the proliferation of agencies concerned with patients is not the only modern threat to the traditional right of patients to expect their confidences to be kept.

\section{Recent threats to confidentiality in medicine}

Legal opinion states that enactment supercedes previous legislation, unless specifically excluded in the terms of the new legislation. Thus, unless specifically mentioned as enjoying exemption, work on STD could be threatened, notwithstanding the Venereal Diseases Regulations, by Acts of Parliament that would permit greater freedom of access in confidential health information.

\section{THE POLICE AND CRIMINAL EVIDENCE BILL} Introduced in 1983, this Bill covered many aspects of the work entailed in pursuing the prosecution of offenders. Clause 10 of the Bill would have empowered the police to examine the medical records of persons suspected of committing a "serious arrestable offence." Mr Christopher Mayhew MP (Home Office) pointed out that the information sought should be strictly related to the alleged crime in question and that the seeking of the information should have the approval of a crown court judge. Some quarters of medicolegal opinion felt, however, that the Bill would enable the police to gain easy access to medical records on the "flimsiest of grounds"." The BMA wrote to all members of parliament ${ }^{14}$ : "There are no safeguards in the Bill to ensure that the information about innocent people will be held in confidence by the police and will be destroyed at the end of the inquiry. There is nothing in the Bill to prevent the police acquiring information in connection with a serious crime and then using the information thereafter in connection with trivial or less serious offences. The clause would allow a judge to issue an order exparte without giving the doctor an opportunity to present a case as to why the application should be refused. Doctors recognise that there are cases when the interest of the community over-rides confidentiality. Nevertheless, such occasions must be clearly spelt out and should be closely defined by parliament on behalf of the people in the community." It was not clear at all that "venereal disease information" would have been exempt. After some very hard work by the BMA, clause 10 was defeated at the report stage of the Bill - that is, at the very last minute. The Bill was enacted in 1984.

THE ACCESS TO PERSONAL FILES BILL

This Bill was to have been introduced in late 1984 as a private members' motion by $\mathrm{Mr}$ Christopher Smith MP as a result of intense lobbying by the " 1984 Campaign for the Freedom of Information." This pres- sure group has the support of such organisations as the Patients Association, the National Association for Mental Health (MIND), and the Community Rights Project. Under the terms of the Bill, individuals would be given the statutory right to have access to information held about them by public authorities. Medical records would not be exempt, though records in departments of genitourinary medicine would probably not have been considered.

Under section 33 of the Supreme Court Act of 1981, persons involved or likely to be involved in litigation against a health authority or one of its employees have the right of access to their medical records, which are held on their behalf by the Department of Health and Social Security (DHSS). It is worthwhile recording the opinion of the BMA on such matters, as stated in their evidence to the Interprofessional Working Group on Access to Personal Health Information. ${ }^{14}$ "We support the right of patients and clients to have access to all information which is held about them on their behalf ..." Various qualifications are listed, and then: "There may in the last resort remain a legal right to seek access to information which has still been withheld. It would be appropriate for such a right to be exercised through the courts, which would decide the issue. We believe that this would arise only exceptionally."

The situation is surely different with regard to records in departments of genitourinary medicine, in which sensitive details of a personal or diagnostic nature are written about third parties. Effective STD medicine cannot be practised without immediate access to data on sexual contacts, and it is unrealistic to expect that this would be anywhere else but in the index patient's notes.

The Access to Personal Files Bill has not yet been debated. The aims of the Campaign for the Freedom of Information may well be altruistic and sensible. Care must be taken, however, to preserve the confidentiality of the contacts of the person seeking access to their medical files.

\section{The Gillick case}

In genitourinary medicine difficulties sometimes arise with regard to suspected or actual STD in girls below the age of 16 years, who present voluntarily for advice and who have already been sexually active. The two principal difficulties devolve around unlawful sexual intercourse and consent to medical treatment. Under section 6 of the Sexual Offences Act (1956), it is an offence for a man or a boy to have intercourse with a girl who has not reached the age of consent (16 years): this is punishable by a maximum penalty of two years' imprisonment. A defence against "unlawful sexual intercourse" is available to the man under 24 years of age if he reasonably believed that the girl was 16 or 
more and he has not been previously convicted of a similar offence.

In terms of consent to medical treatment, a person is a minor until the age of 18 years. Before 1969 this meant that parental consent was required before medical treatment could be undertaken. The Family Law Reform Act, however, in section 8(1) allows for the consent to medical treatment of a person under 16 years old without reference to the parent or guardian. Some areas of the legal profession feel that the treatment of persons under the age of 16 is a grey area under the Act (S Gaskill, personal communication), and in any case, provision has always been made for nonconsensual treatment on grounds of necessity or emergency. Mason and McCall-Smith have discussed the matter in detail. ${ }^{4}$

There is some analogy to be drawn between the practice of STD medicine and contraception in this age group: doctors have often advised such girls to confide in their parent(s), if they have not already done so, but if the girl has refused many have gone ahead and treated anyway. Some practising venereologists have assumed that they have extra protection under the Venereal Diseases Regulations. They have felt that it was their duty to help and respect the girl's confidence if they were concerned that she would not abandon her sexual activities and that relations with her parents had broken down. The statute and case law is not considered to be clear. ${ }^{15}$

In 1974 the DHSS sent out the Family Planning Service Memorandum of Guidance. It recommended that contraceptive services "be ... accessible to young people at risk of pregnancy, regardless of age." Doctors were advised that they would not be in breach of the law if they helped protect young girls against pregnancy and were advised that the girls' parents should not be informed without their permission (it was emphasised, however, that every effort should be made to persuade such girls to inform their parents). In 1980 the DHSS issued a notice $(\mathrm{HN}(80) 46)$ on family planning to area health authorities more or less confirming this position but recommending that doctors should take special care "not to undermine parental responsibility" in the treatment of children. These notices were not so much breaking new ground as merely clarifying a practice many doctors had already been following for some time.

Mrs Victoria Gillick, a Roman Catholic mother of 10, had four daughters under the age of 16 years when the 1980 notice was circulated. She sought an assurance from her local area health authority that none of her daughters under the age of 16 would be given contraceptives without her knowledge and consent. Having organised a petition with a million signatures (and having received a negative reply from the Wisbech Area Health Authority), she took the matter to court on 17 February 1983 . Her claim was rejected by the court of first instance. Summing up in the Queen's Bench division of the high court, Mr Justice Woolfe said: "In many matters concerning our health, we have to rely on doctors to act responsibly and, in this area, it is to be expected that the doctors will exercise their responsibility - which is a heavy one - in a proper manner."16 The matter was then taken to appeal, and in December 1984, Mrs Gillick's claim was upheld.

Lord Justice Parker said that the plaintiff's purpose in bringing the action was to establish the parental rights and duties in respect of girls under $16 .{ }^{17} \mathrm{He}$ made it clear that respectable and responsible people might hold different, strong, and sincere views as to the moral, religious, or ethical questions arising out of the case, but their Lordships were concerned only with the legal position. Lord Parker then went on to discuss the case law and the criminal law pertaining to the parents' rights in this matter. He also felt that it was "wholly incongruous that either the DHSS or the area health authority should provide facilities - that is, family planning advice - which would enable girls under 16 the more readily to enter into sexual intercourse." The law report goes on to state:

"In the final analysis the position was as follows. It was clearly established that a parent or guardian had, as such, a parcel of rights in relation to children in his custody. By statute, such rights could, in general, be neither abandoned nor transferred.

"Such rights included the right to control the manner in which and the place at which the child spent his time. Those rights would be enforced by the Court subject to the right of the Court to over-ride the parental rights to the interest of the child.

"There was no authority of any kind to suggest that anyone other than the Court could interfere with the parents' rights otherwise than by resort to the Courts, or pursuant to specific statutory powers or exceptions."

Lord Parker allowed the appeal, and Lord Justice Fox and Lord Justice Eveleigh delivered concurring judgements: “. . . any doctor who advised a girl under 16 as to contraceptive steps to be taken or afforded contraceptive advice or abortion treatment to such a girl without the knowledge and consent of her parents, save in emergency, infringed the legal rights of the parent or guardian. Save in emergency, the proper course was to seek parental consent or to apply to the court".

The implications for STD work are unknown. Do the Venereal Diseases Regulations and the nature of STD practice set the speciality of genitourinary medicine apart from these considerations? The situation - until Gillick - was different and quite clear. The criminal liability of the doctor as to whether he was aiding and abetting unlawful sexual intercourse was summed up in the British Medical Journal ${ }^{18}$ : the doctor clearly did not have liability. The legal liability of the doctor for examining a minor without parental 
consent is slightly more difficult and is well summarised by Mason and McCall-Smith. ${ }^{4}$ In the Gillick case Lord Parker acknowledged the areas of uncertainty in both these situations: "whether in an individual case a doctor who following the guidance note (of the DHSS) would commit a criminal offence ... had to depend upon the circumstances... A normal preliminary to contraceptive advice and treatment was a vaginal examination, and some contraceptive devices involved in their fitting that which could, without consent, be prima facie indecent assaults. It might be that a doctor who, without the consent of a woman, examined her vagina for medical purposes committed no indecent assault, but there were clearly strong arguments the other way."

Mrs Gillick's wishes as a Christian and as a caring mother are to be respected. She may, indeed, have strong moral justification for her actions. My experience in genitourinary medicine, however, suggests that young girls who attend have been sexually active with one or more partners. These girls are at increased risk of STD, and for the sake of their future health and that of the community it is essential to offer them speedy effective treatment and follow up to ensure cure. As with most potential STD sufferers, breaking confidence will act as a deterrent to presenting for medical consultation. Many girls under the age of 16 are immature, ${ }^{1920}$ and the relationship with their parents has already broken down. It would be counterproductive to involve their parents in the issue, against the girls' express wishes.

The House of Lords overthrew the Court of Appeal decision on 17 October, 1985.

\section{Coercive treatment and compulsory notification of sexually transmitted diseases}

In the final report of the Royal Commission on Venereal Diseases $(1916)^{2}$ the commissioners stated: “... We consider also that any suggestion of compulsory treatment or compulsory continuance of treatment might defeat the object we have in view, which is to secure accurate diagnosis and adequate treatment at the earliest possible moment for the largest number of sufferers. We have come to the conclusion that, at the present time, any system of compulsory personal notification would fail to secure the advantages claimed, and we are of the opinion that better results may be obtained by a policy of education regarding the importance and serious nature of venereal diseases and by adoption of the measures we have already recommended for increasing largely the facilities for diagnosis and treatment." This was published in an age of rampant venereal diseases, poverty, enormous ignorance among the public of these matters, and very little effective treatment.

The various public health acts over the last 100 years have enacted the compulsory notification of communicable diseases. The most comprehensive was the Public Health Act of 1936, and yet both this and the others exclude the venereal and sexually transmitted diseases, with the exception of neonatal gonococcal ophthalmia. The Act of 1968 allows for the compulsory notification of further communicable diseases under the local bylaw legislation and for the compulsory treatment of any person so named. To the best of my knowledge this facility has never been used for STD.

Provision for coercive treatment has been made in the past - during wartime. In 1917 under Defence Regulation 40d a woman could be charged with the offence of transmitting venereal diseases to a serviceman. ${ }^{22}$ The Americans asked for the law to be extended to their troops in the United Kingdom and suggested that the police forces investigate such matters. This and other proposed measures proved to be too oppressive for the British, and the matter was dropped. During the second world war compulsory notification of the sexual contacts of venereal diseases sufferers was enacted under Defence Regulation 33b of 1939 (addendum No 2277, effective 1942). This became notorious among venereologists as it also entailed the coercive examination and treatment of such contacts and in many respects was a failure. ${ }^{23}$ Under the voluntary system that has been in operation in the United Kingdom for over 60 years we have achieved some measure of STD control compared with that of other countries. ${ }^{24}$ The voluntary system certainly suits the British temperament, an important fact to be taken into consideration. In some countries, particularly in the Far East, prostitutes are registered by the police; such countries often have very little STD control. Interestingly, the International Human Rights Convention, under the auspices of the United Nations, rejected the concept of the registration of prostitutes (Singapore, 1959).

Every now and then there are calls in parliament for the compulsory treatment, or notification of, actual or suspected STD sufferers. In 1969 Sir M Galpern MP asked the Minister of Health during parliamentary question time whether the compulsory treatment for STD sufferers should be provided. In a written answer the Minister, the Right Honourable Kenneth Robinson, stated that he had been advised that improving contact tracing facilities would be more effective in the control of STD than compulsory treatment. ${ }^{25}$ Undeterred by, or unaware of this exchange, $\mathrm{Mr}$ Nicholas Winterton MP tabled a motion urging ministers to investigate the idea of compulsory treatment in the 1984-85 parliamentary session. Anyone seeking treatment would have to tell the doctor who they thought they had acquired the disease from: that person could then be liable for prosecution under criminal law. Apparently believing that he has the 
monopoly on concern in this area, he has been quoted as saying "I expect this proposal will get a mixed reaction from the medical profession to begin with, but I am convinced that in the long term the profession will see the benefits of such a move. ${ }^{26}$ Is he also unaware of the remarks of the previous adviser in genitourinary medicine to the DHSS? He said of coercive treatment: "Only a very small number of cases were notified centrally (under Defence Regulations 33B), and the obvious failure of this attempt to introduce central control has been used as the basis for the argument that it would be counterproductive to attempt to impose any element of compulsion or notification into treatment. This has been the view taken by successive advisers to a number of post war governments, and it is believed that the best guarantee that patients will attend clinics for diagnosis and treatment is the knowledge that all details will be absolutely confidential within the clinic."'

Recently, a call has been made for the compulsory notification of sufferers from the acquired immune deficiency sydrome (AIDS). Supported by some 50 back bench MPs, Mrs Jill Knight MP tabled a commons motion calling for such a provision (The Times, February 9, 1984): a common feature of these tabled parliamentary questions and motions seems to be a lack of research into the relevant background of the situation.

\section{Conclusions}

It is obvious that effective and humane practice in genitourinary medicine is under threat from outside forces. Generations of venereologists have agreed that strict confidentiality within this discipline, when dealing with such personal and private matters as sexual practices, is indispensable. Such confidentiality has not only been thought to be humane but also conducive to good STD control. Venereologists will be aware of how, with practice, the attendance of the sexual contacts of STD sufferers can be effected in a discrete yet effective manner. Recent experience with the Police and Criminal Evidence Bill and the Data Protection Bill has shown how quickly our informed and responsible stance on these matters can be challenged with only a few weeks left before enactment. The Police and Criminal Evidence Bill was at the report stage before the BMA secured the amendments to nullify clause 10 . The Data Protection Bill had passed through the Lords and was well on its way through the committee stage before the interprofessional working party's first successful amendments were announced. I have been advised that the Venereal Diseases Regulations do not necessarily afford protection: they can, as it were, be "over-ridden" by new Acts that may not even specifically refer to them. The dividing line between excessive secrecy and confidentiality, which is a narrow one, has been successfuly addressed for 60 years in STD medicine in the United Kingdom, and it is best drawn by this and subsequent generations of "venereologists." Authority is challenged in this age of "social conscience" - and rightly so - but such challenges must be informed. Extreme care must be taken in matters of such importance for public health to avoid hasty emotional judgements; taking the "long view" is of paramount importance.

Is now the time to amend and strengthen Venereal Diseases Regulations to counter this growing problem to allow us to carry out our important work efficiently and unhindered? We will lose ground if we are not seen by prospective patients to be completely discrete.

I thank S Gaskill of the faculty of law; University of Leeds, legal adviser to the Journal of Medical Ethics, for stimulating my interest in this subject and my colleagues in genitourinary medicine in Sheffield for their help.

\section{References}

1. Martin CRA. Law relating to medical practice. 2nd ed. London: Pitman Medical, 1979.

2. Catterall RD. Confidentiality in the National Health Service and in the service for sexually transmitted diseases. British Journal of Venereal Diseases 1980;56:263-6.

3. Thompson IL. The nature of confidentiality. J Med Ethics 1981;5:57.

4. Mason JK, McCall-Smith RA. Law and medical ethics $1 \mathrm{st}$ ed. London: Butterworths, 1983.

5. In: RV Instan (1893), Queen's Bench 450 at 453.

6. Report on Breach of Confidence. Law Commission Report No 110.

7. Central Committee on Medical Ethics of the British Medical Association. Handbook of medical ethics. London: British Medical Association, 1984.

8. Comrie JD. History of Scottish medicine. Vol II, 2nd ed. London: Balliere, Tindall and Cox, 1932:200-7.

9. Committee on Privacy Report. London: HMSO (No 467), 1972. (CMND 5012) (Younger Report).

10. Committee on Data Protection Report. London: HMSO, 1978 (CMND 7341) (Lindop Report).

11. Havard JDJ. Protecting confidentiality. Br Med J 1984; 288:1102-3.

12. Department of Health and Social Security. Draft code on confidentiality of personal health information London: HMSO, (DA(84)25), 1984.

13. City of Birmingham District council $v$ " $O$ " and Another (1983) 3 ALL ER 497, p.503.

14. Anonymous. Data protection. $\mathrm{Br} \mathrm{Med} J$ 1983;286:1592.

15. Anonymous. Dwindling rights. [Editorial]. The Times 1984 December 21:15 (cols 1-3).

16. Anonymous. Mrs Gillick's campaign. [Editorial] The Lancet $1983 ;$ ii, 1346.

17. Law Report. The Times 1984 December 21:9 (col 4).

18. Anonymous. Medicolegal. Contraception and the under-16s. $\mathrm{Br}$ Med J 1980;281:318.

19. Ponting LI. Social aspects of venereal diseases in young people in Leeds and London. British Journal of Venereal Diseases 1963;39:273-7.

20. Keighley E. Venereal diseases in women prisoners. British Journal of Venereal Diseases 1957;33:105-11.

21. Royal Commission on Venereal Diseases. Final Report of the Commissioners. London: HMSO, 1916. 
22. Morton RS. Evolution of venereology as a speciality. In: Holmes KK, Mardh P-A, Sparling PF, Wiesner PJ, eds. Sexually transmitted diseases. 1st ed. New York: McGrawHill, 1985:30-5.

23. Laird SM. Defence regulation 33B Journal of the Royal Sanitary Institute 1964:6B:193.

24. Catterall RD. National strategies for STD control: a UK perspective. In: Holmes KK, Mardh P-A, Sparling PF,
Weisner PJ, eds. Sexually transmitted diseases. New York: McGraw-Hill, 1985:941-5.

25. Robinson K. Parliamentary written answer. House of Commons Official Report (Hansard) February 28; 1968:759:386.

26. Penfold B. Sex spy role for doctors as MP urges law over VD Doctor 1984;Dec 13. 